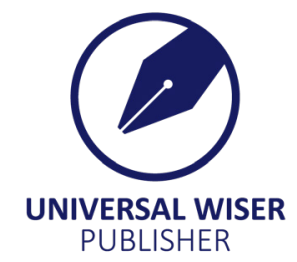

\title{
School and Parental Factors Associated with One-Night Stand, Condom Use at Sexual Debut and Multiple Sexual Partners
}

\author{
Tunde Adeyemo Alabi ${ }^{1 *}$, John Lekan Oyefara ${ }^{2}$, Waziri Babatunde Adisa ${ }^{3}$ \\ ${ }^{1}$ Department of Sociology, University of Lagos, Nigeria; Department of Sociology, University of Cape Town, South Africa \\ ${ }^{2}$ Department of Sociology, University of Lagos, Nigeria \\ ${ }^{3}$ Department of Sociology, University of Lagos, Nigeria \\ E-mail: taalabi@unilag.edu.ng
}

\begin{abstract}
In many countries, risky sexual behaviour appears to have become more common among sexually active young adults due to increasing acceptance of pre-marital sexual behaviour. This poses threat to the sexual and reproductive health of those who engage in same. This study investigated the possible influence of school and parental factors such as time of sexual debut (before or after admission), institutional type, accommodation type (whether campus or off-campus), parental marriage type, parental counselling and family of socialisation on three risky sexual behaviours. These are onenight stand, condom use at first sex and multiple sexual partners. The study adopted cross-sectional survey method. A total of 433 respondents were selected from three stratified tertiary institutions in Lagos State, Nigeria. The study found that institutional type and parents' marriage significantly influenced involvement in one-night stand. The age at sexual debut and parents' marriage type are associated with the use of condom at first sex. Also, while students of polytechnic had more sexual partners than their counterparts in the university and college of education (F: 16.849; p: 0.001), those living inside campus were significantly more likely to have multiple sexual partners than those outside campus (T: -1.995; p: 0.047). The study recommends the need for the management of institutes of higher learning and accommodation providers to improve their physical environment to discourage risky sexual behaviours, and to sensitise young people. Also, parentchild discussion on sex-related matters from both parents especially in polygynous homes is encouraged.
\end{abstract}

Keywords: one-night stand, sexual debut, condom use, multiple sexual partners, school, parents

\section{Introduction}

In many countries, premarital sex has become more prevalent among young adults ${ }^{[1]}$. Researchers have attributed this rise in sexual activity to a number of factors including changing social mores relating to sexuality ${ }^{[2]}$, increasing gender equality ${ }^{[3]}$, as well as delayed marriage ${ }^{[4]}$. Similarly, risky sexual behaviour appears to have become more common among sexually active young adults. One-night stands, early sexual debut, the number and types of sexual partners, and unprotected sexual activity are all examples of what is considered 'risky sexual behaviour' ${ }^{[5]}$, given the dangers they pose to the sexual and reproductive health of engagers ${ }^{[6]}$. This makes it imperative to understand the factors associated with sexual behaviours that may negatively affect the quality of lives of adolescents and youths.

One-night stand is a specific form of casual sex occurring as a spontaneous sexual interaction between strangers or casual acquaintances, without intimate self-disclosure ${ }^{[6,7]}$, and believed to be more widespread in the West ${ }^{[7]}$. As young people in non-Western and developing countries assimilate Western values and attitudes (through movies, music, and the internet), sexual behaviours like one-night stands are becoming widespread in developing countries ${ }^{[8]}$. Sexual debut refers to an individual's first sexual experience ${ }^{[9]}$, which can be 'early' or 'delayed' ${ }^{[10]}$. Sexual debut is 'early' when it occurs before the age of 18 , and late when it occurs from age 20 and above ${ }^{[11]}$. The general agreement in the research literature is that delayed sexual debut is preferable to early sexual debut ${ }^{[12]}$, because of the numerous risks associated with latter. One of these is the low probability of condom use ${ }^{[13]}$.

A number of factors have been identified to explain young people's increasing proclivity for one-night stands, early sexual debut, and multiple sexual partners. These include depression ${ }^{[14]}$, alcohol use ${ }^{[15,16]}$, atypical sexual arousal patterns ${ }^{[17]}$, frequent use of dating / hook-up apps ${ }^{[18]}$, as well as parental factors such as communication and monitoring ${ }^{[19-21]}$. However, there is a paucity of studies in the research literature which have looked into the influence of

Copyright (C2020 Tunde Adeyemo Alabi, et al.

DOI: https://doi.org/10.37256/ser.122020265

This is an open-access article distributed under a CC BY license

(Creative Commons Attribution 4.0 International License)

https://creativecommons.org/licenses/by/4.0/ 
school factors (such as the types of accommodation and institution) on these sexual behaviors. Furthermore, while studies have examined how the family influences youth sexual behaviour e.g. ${ }^{[22]}$, not many studies have explicitly investigated the influence of the family of socialisation and parents' marriage type on sexual behaviours such as one-night stand and multiple sexual partners. This study, therefore, seeks to fill these gaps in the literature, and attempts to answer the following questions. Are institutional type, parental marriage type, parental counselling and family of socialization associated with one-night stand? Does time of sexual debut (before or after university admission), age at sexual debut, parental marriage type and parental counselling influence condom use at first sex? Do groups in institutional type, accommodation type, parental marriage and age at sexual debut vary in number of sexual partners?

\section{Methods}

\subsection{Design and study settings}

The adopted cross-sectional survey design and quantitative method of data collection. The study was conducted in three different tertiary institutions: one university (University of Lagos), one polytechnic (Yaba College of Technology), and one technical college of education (Federal College of Education, Akoka). Tertiary institutions in Nigeria are stratified with universities being the most prestigious, followed by polytechnics, then colleges of education. There are two reasons for selecting these institutions. One, the three institutions are similar in that they are the only federal government-owned university, polytechnic and college of education in Lagos State. Two, the institutions are part of the first generation tertiary institutions in Nigeria. Yaba College of Technology was the first polytechnic in the country (established since 1934). University of Lagos (1962) and Federal College of Education, Akoka (1967) were among the institutions established within the first decade of Nigeria's independence. The study population was composed of undergraduates who were running fulltime programme in the institutions, and had had sex at least once as of the time of the study. Students who had never had sex were excluded from the Study.

\subsection{Sampling, instrument and measures}

A sample size of 450 was selected using Raosoft online sample size calculator. (http://www.raosoft.com/samplesize. $\mathrm{html})$. The proportionate stratified sampling technique was used to determine the number of respondents that was drawn from each institution. The University, constituted $65.5 \%$, a polytechnic comprised $28.6 \%$, while the college of education had a proportion of $5.9 \%$. Sample sizes of 294,129 and 27 respectively were allotted to the institutions.

A total of 433 questionnaires were completed. The structured questionnaire contained 49 questions. The section on socioeconomic characteristics contained 13 basic questions on age, religion, ethnic group, and academic level, nature of secondary school, current relationship status, family type and accommodation type among others. The questionnaire was self-administered due to the sensitivity of the topic.

Early sexual debut was measured as intercourse before age 18. Multiple sexual partners meant having two or more partners 9 months prior to the study. Regarding one-night stand, we asked "Have you ever had sexual intercourse on a one night stand?" with "no" and "yes" options. For condom use at first sex, we asked: "Did you or your partner use condom at your first sex?" with two options: "yes, I / my partners used condom"; "no, none of us used condom". On multiple sexual partners, we asked: "how many sexual partners have you had this year", it was left open.

\subsection{Data analysis}

Chi-square was used to show the bivariate association between the independent variables and two dependent variables: one-night stand and condom use at first sex. Binary logistic regression was used to run the multivariate analysis for the two dependent variables to see the possible effect of other covariates. Analysis of variance was used to test for significant difference in number of sexual partners for groups in age at sexual debut and institution type, while T-test was used to test for the mean difference between those who stayed on campus and those who stayed off-campus, and between those whose parents were monogamous and those who have polygamous parents. Equality of variance assumptions were checked and met.

\subsection{Ethical consideration}

The management of each of the institutions gave approval before the commencement of the research. In addition to the letter of informed consent that accompanied each questionnaire, the researchers ensured that each respondent was verbally informed about the rationale for the study. Prospective respondents who were not interested at the introduction stage were relieved from the exercise; those who lost interest in the process due to the sensitivity of the questions were not compelled to continue. 


\section{Results}

\subsection{Socio-demographic characteristics}

A little above half $(50.3 \%)$ of the respondents were male, and the remaining were female. The mean age and standard deviation were 22.7 and 3.98 respectively. The youngest respondent was 16, and the oldest 35 . More than half (54.4\%) were Yoruba; above one quarter $(26.7 \%)$ of the respondents were Igbo. The majority (56.8\%) attended privately-owned secondary school. Approximately three-quarter (74.5\%) of the respondents have lived on campus before, and $39.2 \%$ currently stay on campus. A little above two-third (68.1\%) of the respondents were raised in a nuclear family, while $31.0 \%$ were raised in an extended family.

\subsection{Sex-related characteristics}

The majority (43.7\%) described their sexual drive as "somewhat strong", while $35.8 \%$ said theirs was "very strong". The majority (40.3\%) had first sex between the age of 16 and 18, and 42.6\% had early sexual debut. Approximately half (49.9\%) had first sex with their boyfriend / girlfriend; $29.4 \%$ had it with just a friend; $12.3 \%$ with schoolmate / classmate. Above half (53.1\%) of the respondents or their partner used condom at first sex. Above one-third (34.2\%) had sex before their tertiary education. More than half (56.3\%) discussed sexually related matters with their parent(s) before sexual debut. Less than two-third (63.1\%) are currently discussing sexual matters with their parents; 48.5\% said that their parents are always reluctant and uncomfortable discussing sexual matters with them. Less than half (45.3\%) had multiple sexual partners between January to September 2017; 43.1\% had experienced "on night stand".

\subsection{Bivariate analysis}

Table 1. Cross-tabulation of parental counselling, family of socialisation, institutional type and one-night stand

\begin{tabular}{|c|c|c|c|}
\hline \multirow[t]{2}{*}{$\begin{array}{l}\text { Access to parental counselling } \\
\text { before sexual debut }\end{array}$} & \multicolumn{2}{|c|}{ Involvement in one night stand } & \multirow[t]{2}{*}{ Total (\%) } \\
\hline & No $(\%)$ & Yes $(\%)$ & \\
\hline No & $92(48.7)$ & $97(51.3)$ & $189(100.0)$ \\
\hline Yes & $150(62.0)$ & $92(38.0)$ & $242(100.0)$ \\
\hline Total & $242(56.1)$ & $189(43.9)$ & $431(100.0)$ \\
\hline$\chi^{2}: 7.631$ & & $p: 0.006$ & \\
\hline Family of socialisation & No $(\%)$ & Yes $(\%)$ & Total (\%) \\
\hline Nuclear Family & $186(63.5)$ & $107(36.5)$ & $293(100.0)$ \\
\hline Extended Family & $55(41.0)$ & $79(59.0)$ & $134(100.0)$ \\
\hline Total & $241(56.4)$ & $186(43.6)$ & $427(100.0)$ \\
\hline$\chi^{2}: 18.827$ & & $p<0.001$ & \\
\hline Institutional type & No $(\%)$ & Yes (\%) & Total (\%) \\
\hline University & $180(63.2)$ & $105(36.8)$ & $285(100.0)$ \\
\hline Polytechnic & 47 (37.9) & $77(62.1)$ & $124(100.0)$ \\
\hline College of Education & $15(68.2)$ & $7(31.8)$ & $22(100.0)$ \\
\hline Total & $242(56.1)$ & $189(43.9)$ & $431(100.0)$ \\
\hline$\chi^{2}: 23.746$ & & $p<0.001$ & \\
\hline Parental marriage type & No $(\%)$ & Yes (\%) & Total (\%) \\
\hline Monogamy & $182(63.6)$ & $104(36.4)$ & $286(100.0)$ \\
\hline Polygyny & $55(39.9)$ & $83(60.1)$ & $138(100.0)$ \\
\hline Total & $237(55.9)$ & $187(44.1)$ & $424(100.0)$ \\
\hline$\chi^{2}: 21.355$ & & $p<0.001$ & \\
\hline
\end{tabular}

It was found that the majority $(62.0 \%)$ of those who had access to parental counselling had never experienced onenight stand. The statistics $\left(\chi^{2}=7.631 ; \mathrm{p}=0.006\right)$ indicate that not having access to parental counselling is significantly associated with experience of one-night stand. Being raised in an extended family is also significantly associated with this sexual behaviour $\left(\chi^{2}=18827 ; \mathrm{p}<0.001\right)$, as $59.0 \%$ of students raised in extended family have been exposed to the act, compared with $36.5 \%$ of those raise in nuclear family. Institutional type was significantly associated with one-night stand 
$\left(\chi^{2}: 23.746 ; \mathrm{p}<0.001\right)$. More than half $(62.1 \%)$ of students in polytechnic have experienced one-night stand at least once, while $36.8 \%$ and $31.8 \%$ of students in the university and college of education respectively have had similar experience. Parental marriage type was significant $(p<0.001)$ as $60.1 \%$ of those whose parents were polygynous had experienced onenight stand compared with $36.4 \%$ of those whose parents were monogamous.

Table 2. Cross-tabulation of time of sexual debut, age at first sex, parental counselling and condom use at sexual debut

\begin{tabular}{cccc}
\hline Time of sexual debut & \multicolumn{2}{c}{ Condom use at sexual debut } & Total (\%) \\
\hline & No (\%) & Yes (\%) & \\
Before admission into tertiary institution & $123(44.6)$ & $153(55.4)$ & $276(100.0)$ \\
After admission into tertiary institution & $65(44.8)$ & $80(55.2)$ & $145(100.0)$ \\
Total & $188(44.7)$ & $233(55.3)$ & $421(100.0)$ \\
$\chi^{2}: 0.003$ & & $p: 0.959$ & \\
Age at sexual debut (in years) & No (\%) & Yes (\%) & Total (\%) \\
15 or below & $57(73.1)$ & $21(26.9)$ & $78(100.0)$ \\
$16-18$ & $54(32.0)$ & $115(68.0)$ & $169(100.0)$ \\
$19-21$ & $46(38.0)$ & $75(62.0)$ & $121(100.0)$ \\
22 or above & $26(60.5)$ & $17(39.5)$ & $43(100.0)$ \\
Total & $183(44.5)$ & $228(55.5)$ & $411(100.0)$ \\
$\chi^{2}: 43.056$ & & $p<0.001$ & \\
Parental counselling before sexual debut & No (\%) & Yes $(\%)$ & Total (\%) \\
No & $89(48.4)$ & $95(51.6)$ & $184(100.0)$ \\
Yes & $99(41.8)$ & $138(58.2)$ & $237(100.0)$ \\
Total & $188(44.7)$ & $233(55.3)$ & $421(100.0)$ \\
$\chi^{2}: 1.824$ & & $p=0.177$ & \\
Parental marriage type & No (\%) & Yes (\%) & Total (\%) \\
Monogamy & $113(39.9)$ & $170(60.1)$ & $283(100.0)$ \\
Polygyny & $73(55.7)$ & $58(44.3)$ & $131(100.0)$ \\
$\chi^{2}: 9.030$ & $186(44.9)$ & $228(55.1)$ & $414(100.0)$ \\
\hline & & $p=0.003$ & \\
\hline
\end{tabular}

The table indicates that time of sexual debut is not significantly associated with condom use at first sex. Age at sexual debut was significantly related with condom use at first sex. $\left(\chi^{2}: 43.056 ; p<0.001\right) .73 .1 \%$ of those who had their first sex at age 15 or below did not use condom, compared with $60.5 \%$ of those who had it age 22 and above. Parental counselling before sexual debut was not associated with condom use at first sex, but parental marriage type was $\left(\chi^{2}: 9.030\right.$; $\mathrm{p}=0.003)$. More than half $(60.1 \%)$ of those whose parents were in monogamous marriage used condom at first sex. More than half (55.7\%) of those whose parents are polygamous did not use condom at first sex. 
Table 3. Test for differences in number of sexual partners for groups in age at sexual debut, nature of institution, nature of accommodation and parental marriage type

\begin{tabular}{|c|c|c|c|c|}
\hline Age at sexual debut & $\mathrm{N}$ & Mean & Std. Deviation & Std. Error \\
\hline 15 years or below & 53 & 4.45 & 4.383 & .602 \\
\hline $16-18$ years & 136 & 3.33 & 3.214 & .276 \\
\hline 19-21 years & 99 & 2.85 & 3.032 & .305 \\
\hline 22 years or above & 32 & 2.34 & 2.391 & .423 \\
\hline \multirow[t]{2}{*}{ Total } & 320 & 3.27 & 3.355 & .188 \\
\hline & DF & Mean Square & $\mathrm{F}$ & Sig. \\
\hline Between Groups & 3 & 39.900 & 3.632 & .013 \\
\hline Within Groups & 316 & 10.985 & & \\
\hline Total & 319 & & & \\
\hline Nature of institution & $\mathrm{N}$ & Mean & Std. Deviation & Std. Error \\
\hline University & 223 & 2.57 & 2.901 & .194 \\
\hline Polytechnic & 87 & 4.89 & 3.805 & .408 \\
\hline College of Education & 19 & 3.68 & 3.074 & .705 \\
\hline \multirow[t]{2}{*}{ Total } & 329 & 3.25 & 3.324 & .183 \\
\hline & $\mathrm{DF}$ & Mean Square & $\mathrm{F}$ & Sig. \\
\hline Between Groups & 2 & 169.715 & 16.849 & .000 \\
\hline Within Groups & 326 & 10.072 & & \\
\hline Total & 328 & & & \\
\hline Accommodation type & $\mathrm{N}$ & Mean & Std. Deviation & Std. Error Mean \\
\hline Off-campus & 128 & 2.80 & 3.204 & .283 \\
\hline Campus & 198 & 3.56 & 3.391 & .241 \\
\hline $\mathrm{T}=-1.995$ & \multicolumn{2}{|c|}{ DF: 324} & \multicolumn{2}{|c|}{$p=0.047$} \\
\hline Parental marriage type & $\mathrm{N}$ & Mean & Std. Deviation & Std. Error Mean \\
\hline Monogamous & 215 & 3.10 & 3.449 & .235 \\
\hline Polygamous & 107 & 3.51 & 3.029 & .293 \\
\hline $\mathrm{T}=-1.061$ & \multicolumn{2}{|c|}{ DF: 320} & \multicolumn{2}{|c|}{$p=0.289$} \\
\hline
\end{tabular}

With respect to age at sexual debut, the statistics $(F=3.632 ; \mathrm{p}=0.013)$ show that there is a difference among groups in age at sexual debut significant in their number of sexual partners. Post Hoc tests show that the difference among those who had first sex at age 15 or below and other age groups is significant. The difference among those debuted at age 16-18, $19-21$ and 22 or above is not significant.

The mean number of sexual partners among students of the university is 2.6, while that of the polytechnic is 4.9. The difference is significant $(\mathrm{F}=16.849 ; \mathrm{p}<0.001)$. There is also a significant difference in the sexual partners had by those who stay off-campus (2.80) and those who stay on campus (3.56). Parental marriage type shows no significant difference. 


\subsection{Multivariate analysis}

Table 4. Binary logistic regression model for sex on one-night stand controlling for age at first sex

\begin{tabular}{|c|c|c|c|c|}
\hline \multirow[b]{2}{*}{ Predictors } & \multirow[b]{2}{*}{ B } & \multirow[b]{2}{*}{ AOR } & \multicolumn{2}{|c|}{$95 \%$ C.I. for $\mathrm{EXP}(\mathrm{B})$} \\
\hline & & & Lower & Upper \\
\hline Step $1^{\text {a }}$ Age at sexual debut & -.080 & .923 & .713 & 1.194 \\
\hline \multicolumn{5}{|l|}{ Institution } \\
\hline University (reference category) & -- & 1.0 & & \\
\hline Polytechnic & .692 & $1.998 * *$ & 1.193 & 3.346 \\
\hline College of Education & -.493 & .611 & .209 & 1.790 \\
\hline \multicolumn{5}{|l|}{ Academic level } \\
\hline First year (reference category) & -- & 1.0 & & \\
\hline Second year & .392 & 1.480 & .788 & 2.779 \\
\hline Third year & .391 & 1.478 & .756 & 2.890 \\
\hline Fourth year & .862 & $2.367 *$ & 1.115 & 5.027 \\
\hline Fifth year & 1.155 & $3.175^{*}$ & 1.244 & 8.104 \\
\hline \multicolumn{5}{|l|}{ Family of socialisation } \\
\hline Nuclear (reference category) & -- & 1.0 & & \\
\hline Extended & .404 & 1.497 & .811 & 2.764 \\
\hline \multicolumn{5}{|l|}{ Description of sexual drive } \\
\hline Very strong (reference category) & -- & 1.0 & & \\
\hline Somewhat strong & -.622 & $.537 *$ & .323 & .891 \\
\hline Not strong & -1.271 & $.280 * * *$ & .149 & .529 \\
\hline \multicolumn{5}{|l|}{ Time of first sex } \\
\hline Before tertiary education (ref. category) & -- & 1.0 & & \\
\hline During tertiary education & -.235 & .791 & .491 & 1.274 \\
\hline \multicolumn{5}{|l|}{ Parental counselling BSD } \\
\hline No (reference category) & -- & 1.0 & & \\
\hline Yes & -.354 & .702 & .450 & 1.094 \\
\hline \multicolumn{5}{|l|}{ Parental marriage type } \\
\hline Monogamy (reference category) & -- & 1.0 & & \\
\hline Polygyny & .620 & $1.860^{*}$ & 1.006 & 3.437 \\
\hline Constant & -.243 & .784 & & \\
\hline
\end{tabular}

It was found that institutional type remained significant predictor even with the presence of other covariates. Students of the polytechnic were 2.0 times more likely to have experienced one-night stand at least once than their counterparts in the university $(\beta=.692 ; \mathrm{p}<0.01)$. Type of parents' marriage was a significant predictor as students whose parents were polygamous were 1.9 times more likely to experience one-night stand than those whose parents were monogamous. The presence of other covariates has reduced the effects of parental counselling and family of socialisation, which were both significantly associated with one-night stand in table 1 .

Other significant factors were sexual drive and academic level. The finding on academic level implies that those at beginning and intermediate level may still be exposed to one-night stand before they graduate if there is no intervention. 
Table 5. Binary logistic regression model for condom use at sexual debut

\begin{tabular}{|c|c|c|c|c|}
\hline \multirow[b]{2}{*}{ Predictors } & \multirow[b]{2}{*}{ B } & \multirow[b]{2}{*}{ AOR } & \multicolumn{2}{|c|}{$95 \%$ C.I. for $\mathrm{EXP}(\mathrm{B})$} \\
\hline & & & Lower & Upper \\
\hline \multicolumn{5}{|l|}{ Age at sexual debut } \\
\hline 15 year or below (ref. category) & -- & 1.0 & & \\
\hline 16-18 years & 1.505 & $4.503 * * *$ & 2.340 & 8.666 \\
\hline 19-21 years & 1.091 & $2.978^{*}$ & 1.486 & 5.969 \\
\hline 22 years or above & .661 & 1.936 & .797 & 4.706 \\
\hline \multicolumn{5}{|l|}{ Description of sexual drive } \\
\hline Very strong (reference category) & -- & 1.0 & & \\
\hline Somewhat strong & -.021 & .980 & .593 & 1.617 \\
\hline Not strong & -.919 & $.399 * *$ & .216 & .738 \\
\hline \multicolumn{5}{|l|}{ Time of first sex } \\
\hline Before university admn. (ref. cat.) & -- & 1.0 & & \\
\hline After university admission & -.257 & .774 & .473 & 1.264 \\
\hline \multicolumn{5}{|l|}{ First sexual partner } \\
\hline Boyfriend / girlfriend (ref. category) & -- & 1.0 & & \\
\hline Just a friend & -.941 & $.390 * * *$ & .233 & .654 \\
\hline Schoolmate / classmate & -.905 & $.404 * *$ & .208 & .788 \\
\hline Others & -1.774 & $.170 * *$ & .057 & .507 \\
\hline \multicolumn{5}{|l|}{ Parental counselling BSD } \\
\hline No (reference category) & -- & 1.0 & & \\
\hline Yes & .296 & 1.345 & .859 & 2.104 \\
\hline \multicolumn{5}{|l|}{ Parental marriage type } \\
\hline Monogamy (reference category) & -- & 1.0 & & \\
\hline Polygyny & -.514 & $.598 *$ & .373 & .960 \\
\hline Constant & .020 & 1.020 & & \\
\hline
\end{tabular}

Time of sexual debut and parental counselling remained insignificantly associated with use of condom at first sex. Age at sexual debut was a significant predictor. Those whose first sex was between age 16-18 were 4.5 more likely to use condom than those who were sexually debuted at age 15 or below $(\beta=1.505 ; \mathrm{p}<0.001)$. Students who were debuted between age 19-21 were 3.0 times more likely than the reference category to use condom at first $\operatorname{sex}(\beta=1.091 ; \mathrm{p}<0.05)$. Parental marriage type was a significant predictor. Students whose parents were polygamous were 1.7 times less likely to use condom at first sex than those whose parents were monogamous.

Regarding other covariates, sexual drive was a significant predictor. Respondents who said that their sexual drive is not strong were 2.5 times less likely to use condom at first sex than the reference category $(\beta=-919 ; p<0.01)$. First sexual partner was a significant predictor. Those who were debuted by just a friend were 2.6 times less likely to use condom than those who were debuted by their boyfriend/girlfriend $(\beta=-.941 ; \mathrm{p}<0.001)$.

\section{Discussion}

This study found that parents' marriage type is a strong predictor of two of the risky sexual behaviours (one-night stand and condom use at sexual debut). This is in consonance with the findings of an earlier study ${ }^{[23]}$ where it was established that children from polygynous homes have favourable attitude towards sexual promiscuity and consequently risky sexual behaviours. In the Nigerian experience, polygynous marriages come with envy and disagreement between / among the wives consequence of which is marital tension and disorganisation. As a result, direct and unanimous monitoring of wards in such families becomes difficult. Polygyny may also lead to absence of the father, and one of the parents living outside the home, consequence of which is risky sexual behaviours ${ }^{[24,25]}$. This study also found that the 
presence of marriage type reduces the predictive power of parental counselling in the model. It is arguable that lack of unanimous monitoring in polygynous marriage reduces the positivity of parent-child communication and relationship. This argument is consistent with earlier findings that positive parent-child communication / relationship helps wards to practice safe sex ${ }^{[20]}$, delays onset of sexual debut ${ }^{[26]}$, and reduces exposure to pre-marital sex ${ }^{[27]}$. In addition, psychological wellbeing, which is an outcome of positive parent-child relationship ${ }^{[28,29]}$, reduces exposure to risky sexual behaviours ${ }^{[30]}$. Moreso, unhappiness which could result from negative parent-child relationship / communication increases the rate of "hook ups" and consequently risky sexual behaviours ${ }^{[31]}$.

Contrary to the findings of this study, parental counselling / communication has been found earlier to be associated with increase in condom use ${ }^{[32]}$. The possible explanation is that age at sexual debut could be an intervening variable. Younger people rarely use contraceptives the first time they have sex, and engage more in risky sexual behaviours ${ }^{[15,33-38]}$. This makes sense since this study found that older age is associated with condom use at first sex and moderately reduces incidence of multiple sexual partners, and earlier studies have established that positive relationship and attachment with parents helps to delay the onset of sexual intercourse ${ }^{[39]}$. It then means that parental counselling before sexual debut contributes indirectly to reduced practice of risky sexual behaviours.

The results of this study reveal that incidences of one-night stand and multiple sexual partners differ by the type of institution. The results of this study show that one-night stands are more prevalent among students at the polytechnic, where more than half of the students surveyed indicated having experienced one-night stand at least once and had 4.9 sexual partners in the 9 months preceding the study. The more likely explanation is that the environment at the polytechnic encourages higher incidence of casual and spontaneous sex compared to the environments at the university and college of education. To give two specific examples, both the university and college of education have well-lit campuses at night, whereas street lights are either non-existent or deficient at the polytechnic; hence, there are many dark spots all over the campus at night. Secondly, both the university and college of education do not allow full-time students stay in the classrooms beyond close of lectures (usually not exceeding 6 p.m.) except during examination period, whereas students at the polytechnic are allowed to stay in some of the classrooms till night, supposedly to allow them study there if they wish to. Consequently, the polytechnic may have unwittingly created an environment that encourages (or at least allows) sexual behaviour to happen on campus.

This study also found that staying on campus increases the likelihood of having more sexual partners. This finding agrees with [40] who argued that the rise in 'hook-up' culture experienced across most American universities can be traced to accommodation policies of universities, from single-sex to co-ed dormitories, which brought young men and women into closer contact. More so, students who stay off-campus with their parent(s) or guardian(s) are likely to be monitored such that their sexual activity is restricted.

\section{Conclusion and implication}

Institution and accommodation types are important school factors in undergraduates' sexual behaviour. Parental marriage type is an important parental factor in undergraduates' sexual behaviour.

Institutions of higher learning need to come to grips with how the physical environments they create either encourage or discourage incidences of unsafe sex practices. As this study has shown, these behaviours tend to occur in much lesser frequency in institutions where campuses are well-lit at night, and where students do not have to study overnight in classrooms. It is important that the managements of educational institutions invest appropriately in campus infrastructure, not only for the educational benefits they bring, but also for the unintended consequences their lack thereof have on students' sexual behaviour. Accommodation providers have a role to play as well. They must make more effort to provide affordable and adequate housing for students on campus, which will ensure that students need not study or sleep in classrooms overnight. In addition, university management should emphasise and maintain sexuality education for students at all levels and not only beginners.

It is equally important that parents understand the potential effects of their own behaviour on the sexual behaviour of their offspring, as well as the limits of their influence. Parents in polygamous marriage need to ensure unanimous monitoring, and positive communication with their wards about sexual matters. 


\section{References}

[1] Pew Research Center. Global attitudes survey. The Pew Research Center, Washington, DC; 2013.

[2] Techasrivichien T, Darawuttimaprakorn N, Punpuing S, Musumari PM, Lukhele BM, El-Saaidi C, Suguimoto SP, Feldman MD, Ono-Kihara M, Kihara M. Changes in sexual behavior and attitudes across generations and gender among a population-based probability sample from an urbanizing province in Thailand. Archives of Sexual Behavior. 2016; 45: 367-382.

[3] Baumeister RF, Mendoza JP. Cultural variations in the sexual marketplace: Gender equality correlates with more sexual activity. The Journal of Social Psychology. 2011; 151(3): 350-360.

[4] Wellings K, Collumbien M, Slaymaker E, Singh S, Hodges Z, Patel D, Bajos N. Sexual behaviour in context: A global perspective. The Lancet. 2006; 368(9548): 1706-1728.

[5] Dimbuene ZT, Emina JB, Sankoh O. UNAIDS 'multiple sexual partners' core indicator: Promoting sexual networks to reduce potential biases. Global health action. 2014; 7(1): 23103.

[6] Wentland JJ, Reissing E. Casual sexual relationships: Identifying definitions for one night stands, booty calls, fuck buddies, and friends with benefits. The Canadian Journal of Human Sexuality. 2014; (3): 167-177.

[7] Kaspar K, Buß LV, Rogner J, Gnambs T. Engagement in one-night stands in Germany and Spain: Does personality matter? Personality and Individual Differences. 2016; 92: 74-79.

[8] Huang Y. Sexuality and everydayness in a transnational context: Toward a re-imagined West-China relationship. Culture, Health and Sexuality. 2017; 19(6): 667-679.

[9] Lanier Y, Hettenbach J, Stoute K, Hollender L, Sutherland G, Stewart J. "It was a Learning Experience": Lessons learned from young African American men and women's sexual debut. The Journal of the Association of Nurses in AIDS Care: JANAC. 2017; (5): 668.

[10] Donenberg GR, Bryant FB, Emerson E, Wilson HW, Pasch KE. Tracing the roots of early sexual debut among adolescents in psychiatric care. Journal of the American Academy of Child \& Adolescent Psychiatry. 2003; 42(5): 594-608.

[11] World Health Organization. Sexual health, human rights, and the law. Geneva; 2015.

[12] Fortenberry JD. Sexual learning, sexual experience, and healthy adolescent sex. New Directions for Child and Adolescent Development. 2014; 144: 71-86.

[13] Orbe MP, Johnson AL, Kauffman LD, Cooke-Jackson AF. Memorable first time sexual experiences: Gendered patterns and nuances. Communication Quarterly. 2014; 62(3): 285-307.

[14] Lin CC, Lee YT, Yang HJ. Risky sexual behaviors as correlates of depression and suicidal ideation among male HIV test-seekers at a voluntary counseling and testing facility in Taiwan. Asia Pacific Journal of Public Health. 2017; (3): 219-228.

[15] Vasilenko SA, Lanza ST. Predictors of multiple sexual partners from adolescence through young adulthood. Journal of Adolescent Health. 2014; 55(4): 491-497.

[16] Pedersen W, Tutenges S, Sandberg S. The pleasures of drunken one-night stands: Assemblage theory and narrative environments. International journal of drug policy. 2017; 49: 160-167.

[17] Velten J, Scholten S, Graham CA, Margraf J. Unprotected intercourse and one-night stands: Impact of sexual excitation, sexual inhibition, and atypical sexual arousal patterns on risky sexual behaviors in women. The Journal of Sexual Medicine. 2016; 13(3): 361-373.

[18] Choi EP, Wong JY, Lo HH, Wong W, Chio JH, Fong DY. The association between smartphone dating applications and college students' casual sex encounters and condom use. Sexual \& reproductive healthcare. 2016; 9: 38-41.

[19] Wight D, Williamson L, Henderson M. Parental influences on young people's sexual behaviour: A longitudinal analysis. Journal of adolescence. 2006; 29(4): 473-494.

[20] Kunnuji MO. Parent-child communication on sexuality-related matters in the city of Lagos, Nigeria. Africa Development. 2012; 37(3): 41-58.

[21] Oluyemi JA, Yinusa MA, Abdullateef R, Kehinde K, Adejoke J. Parental influence on adolescent sexual behaviour among secondary school students in Ogbomoso, Nigeria. African Journal of Social Work. 2017; 7(1): 37-43.

[22] Rupp R, Rosenthal SL. Parental influences on adolescent sexual behaviors. Adolescent medicine: state of the art reviews. 2007; 18(3): 460-470.

[23] Owuamanam DO, Bankole MO. Family type and attitude to sexual promiscuity of adolescent students in Ekiti State, Nigeria. European Scientific Journal. 2013; 9(17).

[24] Pilgrim NA, Ahmed S, Gray RH, Sekasanvu J, Lutalo T, Nalugoda F, Serwadda D, Wawer MJ. Family structure effects on early sexual debut among adolescent girls in Rakai, Uganda. Vulnerable children and youth studies. 2014; 9(3): 193-205.

[25] Ningpuanyeh WC, Sathiya Susuman A. Correlates of early sexual debut and its associated STI / HIV risk factors 
among sexually active youths in Malawi. Journal of Asian and African Studies. 2017; 52(8): 1213-1224.

[26] Okigbo CC, Kabiru CW, Mumah JN, Mojola SA, Beguy D. Influence of parental factors on adolescents' transition to first sexual intercourse in Nairobi, Kenya: A longitudinal study. Reproductive health. 2015; 12(1): 73.

[27] Shabrina CH, Nursasi AY. Correlation between parent-adolescent communication and adolescents' premarital sex risk. Enfermeria clinica. 2018; 28: 51-54.

[28] Broberg M. Young children's well-being in Finnish stepfamilies. Early Child Development and Care. 2012; 182(3-4): 401-415.

[29] Bireda AD, Pillay J. Perceived parent-child communication and well-being among Ethiopian adolescents. International Journal of Adolescence and Youth. 2018; 23(1): 109-117.

[30] Bersamin MM, Zamboanga BL, Schwartz SJ, Donnellan MB, Hudson M, Weisskirch RS, Kim SY, Agocha VB, Whitbourne SK, Caraway SJ. Risky business: Is there an association between casual sex and mental health among emerging adults? Journal of Sex Research. 2014; 51(1): 43-51.

[31] Marelich WD, Graham JL. Social exchange and social / physical topography of one-night stands in college-age students. Electronic Journal of Human Sexuality. 2013; 16.

[32] Tuason IC, Bernarte R, Dong F. The relationship of religion, religiosity, and parental communication in the sexual behaviors of Filipinos aged 18-25 years in the United States and the Philippines. Asian / Pacific Island Nursing Journal. 2017; 2(4): 124-132.

[33] Wang B, Davidson P. Sex, lies, and videos in rural China: A qualitative study of women's sexual debut and risky sexual behavior. Journal of Sex Research. 2006; 43(3): 227-235.

[34] Ohalete N. Adolescent sexual debut: A case for studying African American father-adolescent reproductive health communication. Journal of Black Studies. 2007; 37(5): 737-752.

[35] Zuma K, Setswe G, Ketye Y, Mzolo T, Rehle T, Mbelle N. Age at sexual debut: a determinant of multiple partnership among South African youth. African journal of reproductive health. 2010; 14(2): 47-54.

[36] Onsomu EO, Kimani JK, Abuya BA, Arif AA, Moore D, Duren-Winfield V, Harwell G. Delaying sexual debut as a strategy for reducing HIV epidemic in Kenya. African Journal of reproductive health. 2013; 17(2): 46-57.

[37] Heywood W, Patrick K, Smith AM, Pitts MK. Associations between early first sexual intercourse and later sexual and reproductive outcomes: A systematic review of population-based data. Archives of sexual behavior. 2015; 44(3): 531569.

[38] Lara LA, Abdo CH. Age at time of initial sexual intercourse and health of adolescent girls. Journal of Pediatric and Adolescent Gynecology. 2016; 29(5): 417-423.

[39] Peltzer K, Pengpid S. Early sexual debut and associated factors among in-school adolescents in six Caribbean countries. The West Indian Medical Journal. 2015; 64(4): 351.

[40] Heldman C, Wade L. Hook-up culture: Setting a new research agenda. Sexuality Research and Social Policy. 2010; 7(4): 323-333. 